\title{
Fabrication of Bioactive Coatings on Steel Substrates by Electro-Spark Deposition (ESD) and Micro-Arc Oxidation (MAO) Methods
}

\author{
M. S. Yilmaz*, A. Çakir, A. Ribalko, K. Korkmaz \\ Gebze Institute of Technology, Department of Materials Science and Engineering, 41400 Gebze, Kocaeli

\begin{abstract}
In the present study, first Ti6Al4V alloy was deposited on steel (AISI 1060) surfaces by using ESD method. The optimum electrical parameters for the coating process were investigated to obtain high quality coatings. Then, in order to gain bio-compatibility and obtain second layer, which was coated with hydroxyapatite (HAp), MAO technique was applied on the present coating. Resulting duplex layers were characterized with X-ray diffraction (XRD) and scanning electron microscopy (SEM) with energy dispersive X-ray spectroscopy (EDX) analysis together with surface roughness, coating thickness, scratch tests and hardness tests.
\end{abstract}

DOI: $10.12693 /$ APhysPolA.127.1277

PACS: 81.15.-z , 81.05.Bx , 81.05.-t , 81.16.Pr

\section{Introduction}

It has been known that the bioactivity is crucial for implant materials. Coating of stainless steel or titanium alloys with a hydroxyapatite (HAp) layer is a promising method to obtain a biocompatible surface for biomedical applications [1]. The aim of the present study is to achieve coating of the steel surfaces with HAp. Thus, duplex coating technologies such as Electro-Spark Deposition (ESD) and Micro-Arc Oxidation (MAO) were used.

Electro-Spark Deposition (ESD) or Electro-Spark Alloying (ESA) is one of the surface modification techniques which uses high current/low voltage electrical pulses [2]. The basic principle of this method is based on a mass transfer from the treating electrode (anode) onto the work-piece (substrate, cathode electrode) by electrical discharges. However, both the anode and the cathode materials must be electrically conductive due to the fact that electrical pulses discharge. This technique provides better physical and chemical properties of metal surfaces. Some of these benefits are: great hardness and wear resistance, small heat affected zone (HAZ) on working-piece, strong metallurgical bonds (substrate and coating), low coast and easy to use [3].

Micro-Arc Oxidation (MAO), also known as plasma electrolytic oxidation (PEO), is a coating technique on valve metals such as $\mathrm{Al}, \mathrm{Mg}, \mathrm{Ti}, \mathrm{Zr}$ etc. In this coating process, a ceramic oxide layer grows on the metal surface at potentials above the dielectric breakdown voltage of the first metal oxide layer resulting in the development of series of electrical discharges [4]. The MAO process is a very useful method to achieve a bio-compatible surface on the materials due to the fact that this oxide layer is effective for improvement of a bioactive surface with HAp layer [1].

\footnotetext{
${ }^{*}$ corresponding author; e-mail: msyilmaz@gyte.edu.tr
}

\section{Experimental}

The present study consists of two stages. In the first phase, the ESD coating process was carried out in order to produce a titanium alloys layer on the steel samples. After the best electrical parameters of ESD process were determined, the suitable samples were prepared for micro-arc oxidation process. In the second phase, to achieve the HAp layer, the MAO process was applied to the steel samples coated with titanium alloy layer and then the development of HAp-phase layer on the surfaces was examined.

In the first part of the study, the properties of ESD coating such as roughness, thickness and relative mass gain were determined and also the phase structure of the coating was studied by XRD patterns. In the second part of the study, in a similar way, roughness, thickness, hardness and adhesion strength properties of duplex coatings (ESD+MAO) were determined and then microstructure and phase distribution of coatings were investigated by using XRD, SEM and EDX analysis.

In the present study, a special ESD machine [5], equipped with an electrode, was employed. AISI 1060 steel substrates (cathode) with a size of $20 \times 20 \mathrm{~mm}^{2}$ and titanium alloy (Ti6Al4V) (anode) were used in the ESD coating experiments. In order to obtain a better coating layer on the samples, the electrical parameters of ESD process were determined by literature review and experimental studies. Before the experimental studies, all samples were mechanically ground with 200-1200 mesh emery papers and cleaned ultrasonically with acetone.

During the experiments, the following pulse parameters were used: pulse current amplitude of $100-400 \mathrm{~A}$ and rectangular/triangular pulse form (shape). Accordingly, electrical charge $(2000 \mathrm{mC})$, system voltage $(17 \mathrm{~V})$, coating rate $\left(60 \mathrm{sec} / \mathrm{cm}^{2}\right)$, pulse duration $(50 \mu \mathrm{s})$ and vibration frequency of the electrode holder $(100 \mathrm{~Hz})$ were kept constant. The pulse energy and pulse duration were determined with an oscilloscope (Tektronix TDS 220). After the characterization of ESD coatings, the optimal 
parameters of ESD process were used to prepare samples for MAO process.

For the MAO coating processes, a bipolar pulsed $\mathrm{AC}$ power $(100 \mathrm{~kW})$ supply was employed. In the experiments of MAO process, voltage was applied as $U_{c}=140 \pm 10 \mathrm{~V}$ and $U_{a}=140 \pm 10 \mathrm{~V}$. The current density (flux), which was set in respect to the area of samples surfaces, was $12.5 \mu \mathrm{F} / \mathrm{cm}^{2}$. The processing time was chosen as 6,8 and 10 minutes to examine the development of HAp phase on the sample surfaces. These samples were called as A (6 min.), B ( 8 min.) and $\mathrm{C}$ (10 min.). Electrolyte solution was prepared by mixing $0.02 \mathrm{M} \beta$-glycerophosphate disodium $\left(\beta-\mathrm{GPNa}_{2}\right.$, $\mathrm{C}_{3} \mathrm{H}_{5}(\mathrm{OH})_{2} \mathrm{PO}_{4} \mathrm{Na}_{2}$ ) and $0.2 \mathrm{M}$ calcium acetate (CA, $\left.\mathrm{Ca}\left(\mathrm{CH}_{3} \mathrm{COO}\right)_{2}\right)$ in distilled water.

The surface roughness measurement was performed by using profilometer (SJ-400 Mitutoyo) with a precision of $0.01 \mu \mathrm{m}$ after the ESD and the MAO processes. During ESD coating processes, the mass gain of substrates (cathode) was measured by using a balance (Metter Toledo 200) which has $0.001 \mathrm{mg}$ sensitivity. The Scratch test was applied to analyze the adhesion strength properties of the coatings by using a micro/macro scratch tester (Nanovea Series). The test parameters were chosen as $100 \mathrm{~N} / \mathrm{min}$ (loading rate) and $8 \mathrm{~mm} / \mathrm{min}$ (sample speed). Microstructure and surface morphology of the coatings were investigated by using a scanning electron microscopy (SEM, Philips XL30 SFEG) with energy dispersive X-ray spectroscopy (EDX). The phase composition and micro-structure of the samples were investigated by using X-ray diffractometer (Rigaku D-MAX 2200) patterns. XRD analyses were conducted in the range of $20-90^{\circ}$ with a step increment of 0.02 and account time of 1 second. Hardness measurements were performed on cross section at a load of $5 \mathrm{~g}$ and loading time of $5 \mathrm{~s}$ with a micro-hardness tester (Mitutoyo Micro Wizhard).

\section{Results and discussion}

The relative mass gain in substrates, roughness of surfaces and thickness of coatings as a function of pulse current amplitude and pass number (number of coating layer) are shown in Fig. 1. The relative mass gain (Fig. 1a) decreases while the pass number and current amplitude increase. As the pass number and pulse current amplitude increase, roughness (Fig. 1b) and thickness (Fig. 1c) values of coatings rise as well. These behaviors are characteristic of the ESD coating process $[3,5]$. It is clear that the properties of the MAO process depend on the quality of the previous ESD process and it is shown that the coating number (pass number) of 5 and pulse current amplitude of $300 \mathrm{~A}$ are optimum pulse parameters in the ESD coating process (Fig. 1a-1c).

The XRD patterns of ESD coatings are illustrated in Fig. 2a. From the examination of these XRD patterns, it can be deduced that the change of the electrical parameters of ESD coating do not significantly effect the phase structure of coating. According to the patterns, the coating is mainly composed of $\mathrm{AlFe}_{3}, \mathrm{TiN}$ and $\mathrm{TiO}_{2}$ phases.

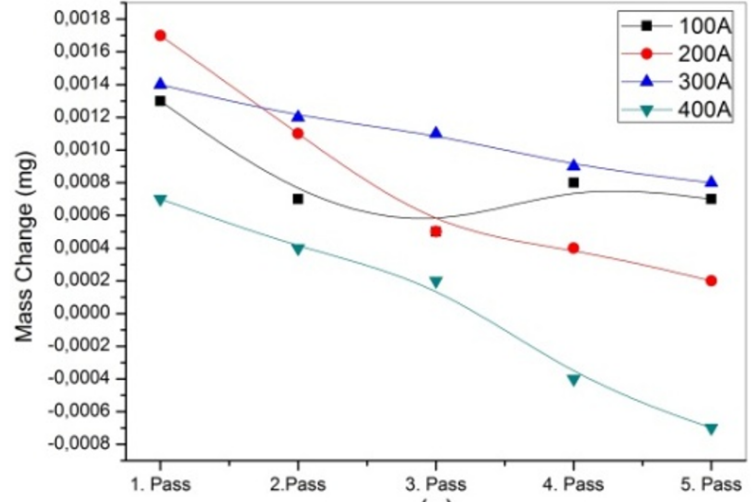

(a)

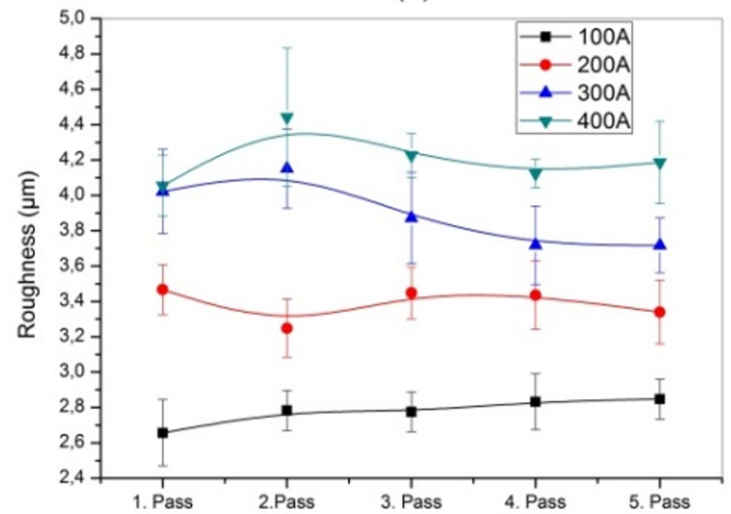

(b)

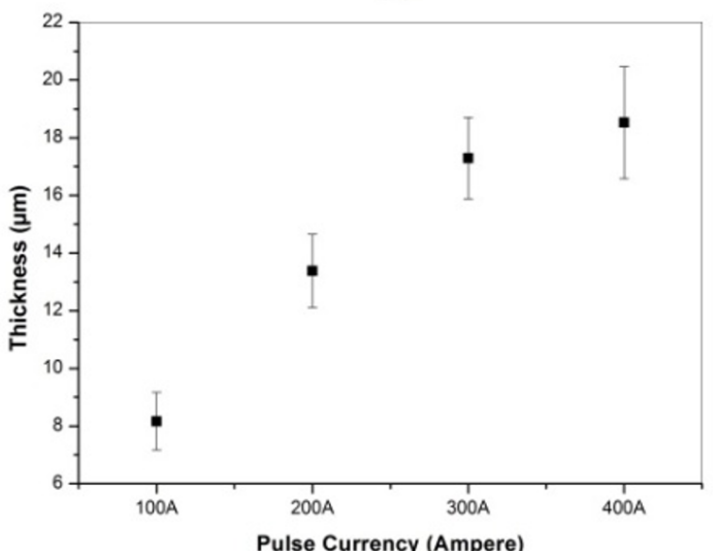

(c)

Fig. 1. The variation of mass transfer (a), surface roughness (b) and coating thickness (c) of samples, with the change of pass number and pulse current amplitude.

It is believed that $\mathrm{AlFe}_{3}$ phase is present as a result of the alloying of the Fe element in the steel substrate and the $\mathrm{Al}$ element in the electrode material. Furthermore, it is thought that the phases of $\mathrm{TiN}$ and $\mathrm{TiO}_{2}$ are formed due to the ESD process performed in air $[3,6]$.

The XRD patterns of the duplex (ESD+MAO) coatings after the MAO process are illustrated in Fig. $2 \mathrm{~b}$. It is shown that the coatings of three samples are mainly composed of the $\mathrm{AlFe}_{3}$ (predominant), $\mathrm{TiN}, \mathrm{TiO}_{2}, \mathrm{Fe}_{2} \mathrm{Ti}$ and $\mathrm{Al}_{82} \mathrm{Fe}_{18}$ phases. Their structures are quite different from that of ESD coating due to the fact that they mainly 
contain an amorphous phase. It is believed that it depends on rapid solidification which takes place in microarc channels during the MAO process. As the processing time increases, the relative intensity of the $\mathrm{TiO}_{2}$ phase decreases. However the formation of the HAp phase did not occur. On the contrary, it is expected that development of HAp phase, as the amorphous phase, takes place. Thus, the focus was made on the rates of $\mathrm{Ca} / \mathrm{P}$ in the EDX analyses, in order to observe the development of the HAp $\left(\mathrm{Ca}_{5}\left(\mathrm{PO}_{4}\right)_{3}(\mathrm{OH})\right)$ phase.

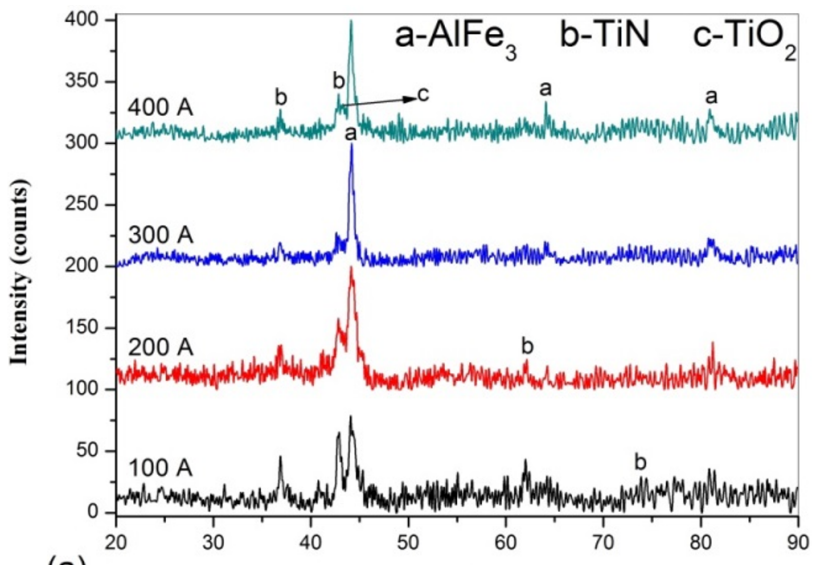

(a)

$2 \theta$ (deg.)

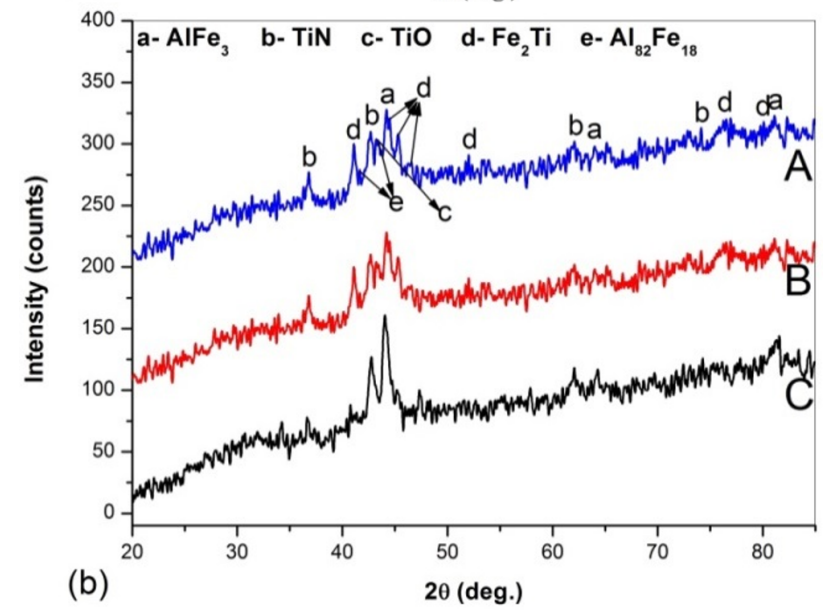

Fig. 2. XRD analysis of coatings after ESD (a) and MAO (b) in the experiments.

After the MAO process, a scratch test was applied to the duplex coating to determine the adhesion strength of coating. The adhesion strength of MAO coating was very poor, as expected. However, a failure in the ESD coating occurred when the critical load reached $66 \mathrm{~N}$ (Fig. 3). The ESD coating exhibits excellent adhesion strength compared to the MAO coating. It is clear that this results from the fact that the ESD coating is thicker than the MAO coating and the ESD coating has a strong metallurgical bond resulting in the alloying of the coating and steel substrate $[6,7]$.

In the Fig. 4, the roughness of surface, the thickness and the hardness of ESD and MAO coatings are presented to compare two coatings. As a characteristic of

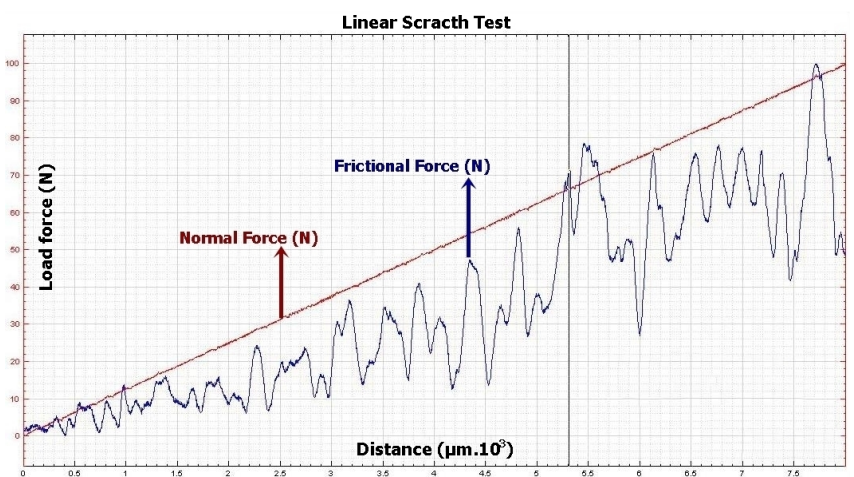

Fig. 3. The loads (normal and frictional)- distance curves for scratch test.

MAO, the values of roughness (Fig. 4a) and thickness (Fig $4 \mathrm{~b}$ ) rise with the increase of processing time, which is in accord with the nature of the process $[8,9]$. The average hardness of the MAO coating could not be detected due to the fact that it was very weak. However, the average hardness of the ESD layer is approximately 5 times harder than that of AISI 1060 steel substrate and the average hardness of Heat Affected Zone (HAZ) is about 2 times harder than that of substrate (Fig. 4c).

It is believed that the development of HAp phase could not be detected since XRD pattern is a very noisy pattern and also the MAO coating consists of mainly amorphous phases. Therefore, the focus was made on the elemental distribution (in atomic weight percentage) in the EDX analysis, on the surface and cross-section of coatings. The effect of the process time on the surface morphologies of the coated sample A (Fig. 5a), sample B (Fig. 5b), sample $\mathrm{C}$ (Fig. 5c) and also the regions where the EDX analyses were performed, are shown in Fig. 5. The results of these analyses are presented in Table I. It is known that the $\mathrm{Ca} / \mathrm{P}$ ratio must be very close the stoichiometric composition of 1.67 in the coating with biocompatibile HAp phase $[8,10]$. It seems that as the MAO processing time increases, the $\mathrm{C} / \mathrm{P}$ ratio rises according to the results of EDX analysis. Value close to 1.76 is achieved in the coating of $\mathrm{C}$ sample (10 min). This means, that it is possible to reach value of 1.67 of $\mathrm{Ca} / \mathrm{P}$ ratio for a longer $\mathrm{MAO}$ process time.

EDS elemental analysis of the surface of samples which are given in

TABLE I

Fig. 5 (atomic weight \%).

\begin{tabular}{c|c|c|c}
\hline \hline Element & $\mathrm{A}$ & $\mathrm{B}$ & $\mathrm{C}$ \\
\hline $\mathrm{O}$ & 32.68 & 34.47 & 40.39 \\
$\mathrm{P}$ & 16.77 & 7.36 & 7.52 \\
$\mathrm{Ca}$ & 12.93 & 7.11 & 9.91 \\
$\mathrm{Ti}$ & 7.86 & 28.88 & 0.55 \\
$\mathrm{Ca} / \mathrm{P}$ ratio & 0.77 & 0.97 & 1.32
\end{tabular}

The selected areas of EDX analysis (Fig. 6a) and line scanning EDX analysis (Fig. 6b) on the cross-section of coating of sample-C are given below. Results of the se- 

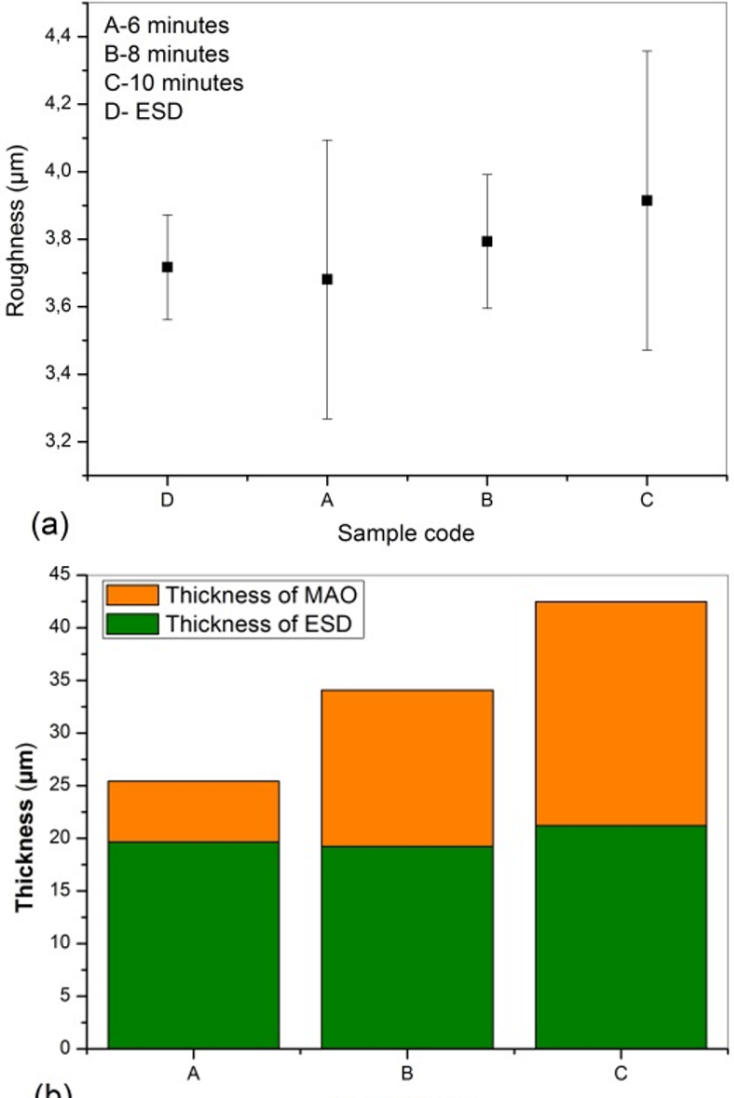

(b)

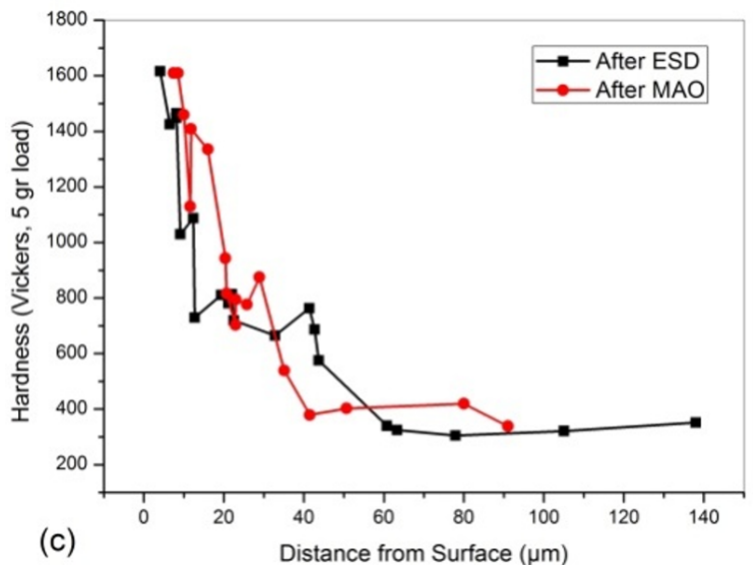

Fig. 4. The comparison of ESD and MAO coating characteristics such as surface roughness (a), coating thickness (b) and hardness (c) of samples.

lected areas, which are seen in Fig. 6a, are presented in Table II. The areas 1 and 2 were chosen at the MAO coating layer for investigations (Table II). The MAO coating was composed of $\mathrm{C}, \mathrm{O}, \mathrm{Ti}, \mathrm{Fe}, \mathrm{Al}, \mathrm{P}$ and $\mathrm{Ca}$ elements. The $\mathrm{Ti}, \mathrm{Al}$ and $\mathrm{Fe}$ elements are originated from the ESD alloying layer, which was obtained by using the electrode material (Ti6Al4V) and the steel substrate (AISI 1060). It is clear that the $\mathrm{C}, \mathrm{O}, \mathrm{Ca}$ and $\mathrm{P}$ elements are originated from the electrolyte $\left(\mathrm{C}_{3} \mathrm{H}_{5}(\mathrm{OH})_{2} \mathrm{PO}_{4} \mathrm{Na}_{2}\right)$ and $\left.\mathrm{Ca}\left(\mathrm{CH}_{3} \mathrm{COO}\right)_{2}\right)$. Considering the EDX analysis of
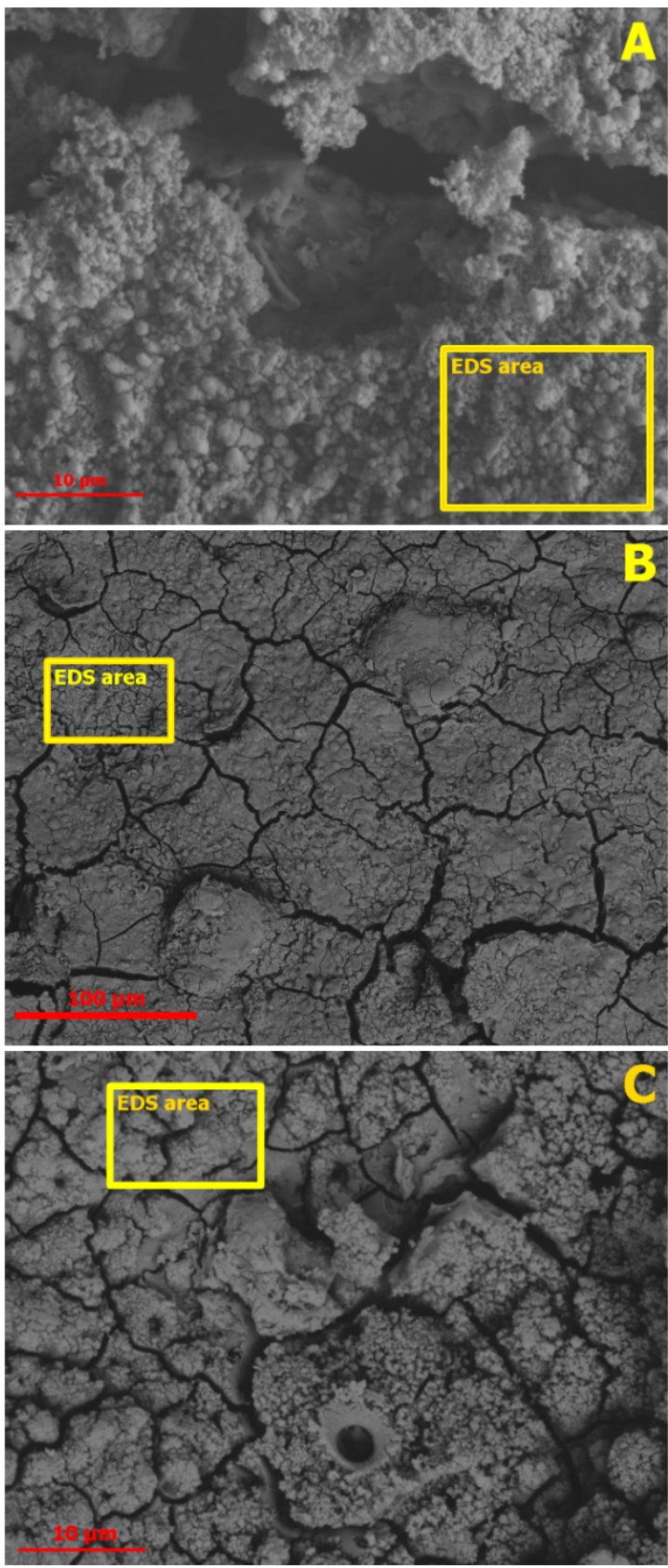

Fig. 5. Surface morphologies of MAO coatings produced during different process times; $6 \min (\mathrm{A})$, $8 \mathrm{~min}(\mathrm{~B})$, and $10 \mathrm{~min}(\mathrm{C})$ and their EDX analysis areas.

areas 3 and 4, which only contain $\mathrm{C}, \mathrm{O}, \mathrm{Ti}, \mathrm{Fe}$ and $\mathrm{Al}$ elements, it can be said that these regions belong to ESD coating layer. These results show that XRD patterns were composed of $\mathrm{AlFe}_{3}$ and $\mathrm{TiO}_{2}$ phases. According to the result of the EDX analysis of the spot 5, it can be said that this region belongs to the HAZ region, which has been formed between the ESD alloying layer and the steel substrate by diffusion of $\mathrm{Al}$ and $\mathrm{Ti}$ elements. It is clear that the area of 6 belongs to steel substrate due to fact that it only consist of Fe and $\mathrm{C}$ elements. 


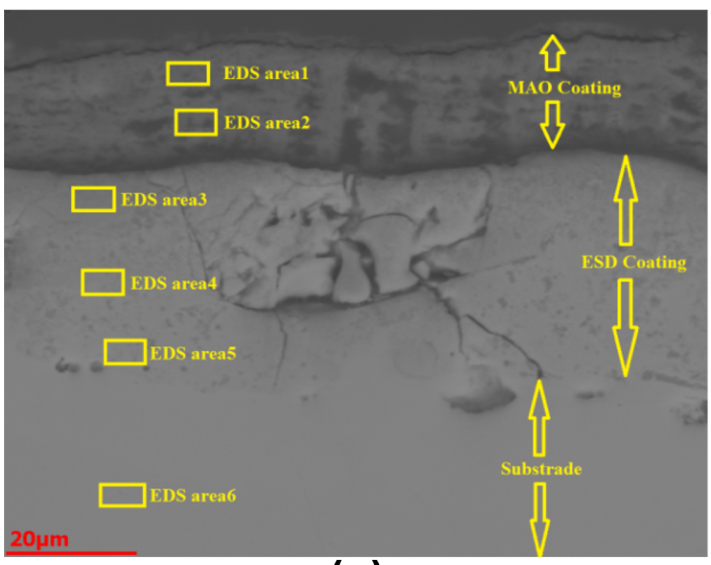

(a)

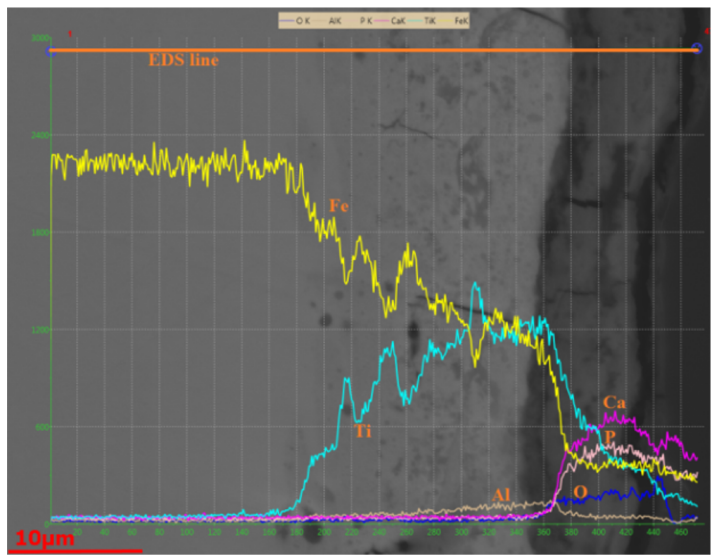

(b)

Fig. 6. The selected areas of EDX analysis (a) and Line-scan of Sample-C (b).

EDX elemental analysis of the cross-sectional ar- TABLE II eas of Sample-C (atomic weight \%).

\begin{tabular}{c|c|c|c|c|c|c}
\hline \hline Element & Area1 & Area2 & Area3 & Area4 & Area5 & Area6 \\
\hline $\mathrm{C}$ & 24.2 & 36.25 & 12.01 & 10.58 & 14.05 & 14.21 \\
$\mathrm{O}$ & 51.78 & 42.61 & 14.6 & 9.22 & - & - \\
$\mathrm{Ti}$ & 4.17 & 5.18 & 27.16 & 26.86 & 18.35 & - \\
$\mathrm{Fe}$ & 5.08 & 4.95 & 27.49 & 39.22 & 64.97 & 84.77 \\
$\mathrm{Al}$ & 0.08 & 1.12 & 3.06 & 3.1 & 1.82 & - \\
$\mathrm{P}$ & 6.01 & 5.67 & - & - & - & - \\
$\mathrm{Ca}$ & 7.96 & 4.21 & - & - & - & - \\
$\mathrm{Ca} / \mathrm{P}$ ratio & 1.32 & 0.74 & - & - & - & -
\end{tabular}

\section{Conclusion}

In this study, the ESD and MAO coating processes were successfully applied to AISI 1060 steel substrate in order to obtain a layer with HAp phase. The following results can be drawn from this research:

- Better results have been found in studies with $300 \mathrm{~A}$, in terms of mass transfer efficiency. Roughness and thickness values of coatings increase with the rise of current amplitude.
- Changes in electrical parameters did not have significant effects on the phase structure of the coatings. While $\mathrm{AlFe}_{3}$ is the dominant phase in the microstructure, TiN and $\mathrm{TiO}_{2}$ peaks were also observable.

- The ESD coating exhibits excellent adhesion strength compared to the MAO coating.

- In the MAO processes as the process time increases, the values of roughness and thickness rise.

- In the micro-hardness tests carried out before and after the MAO process, it was understood that the hardness value of the previous ESD coating did not change. Besides, it was found that the hardness of ESD layer was five times stronger than that of the steel substrate.

- With the help of EDX analysis made on the surface and cross section of the coating, it was determined that $\mathrm{Ca} / \mathrm{P}$ ratio necessary for the formation of HAp phase in the coatings would be achieved with the increase of MAO process time.

\section{Acknowledgments}

This research work was financially supported by Scientific Research Project (BAP) program of Gebze Institute of Technology (No, A-25 2013). The authors express their thanks to technicians Adem Sen and Ahmet Nazim for their kind assistance during XRD and SEM experimental studies.

\section{References}

[1] Y. Han, J.F. Sun, X. Huang, Electrochem. Commun. 10, 510 (2008).

[2] K. Korkmaz, H.I. Bakan, Kovove Mater. 48, 153 (2).

[3] M.S. Yılmaz, E.A., O. Sahin, E.S. Kayalı, Acta Phys. Pol. A 125, 593 (2014).

[4] J. Martin, A. Melhem, I. Shchedrina, T. Duchanoy, A. Nomine, G. Henrion, T. Czerwiec, T. Belmonte, Surf. Coat. Tech. 221, 70 (2013).

[5] A.V. Ribalko, K. Korkmaz, O. Sahin, Surf. Coat. Tech. 202, 3591 (2008).

[6] S. Durdu, S.L. Aktug, K. Korkmaz, Surf. Coat. Tech. 236, 303 (2013).

[7] C.B. Tang, D.X. Liu, Z. Wang, Y. Gao, Appl. Surf. Sci. 257, 6364 (2011).

[8] S. Abbasi, M.R. Bayati, F. Golestani-Fard, H.R. Rezaei, H.R. Zargar, F. Samanipour, V. ShoaeiRad, Appl. Surf. Sci. 257, 5944 (2011).

[9] A.L. Yerokhin, X. Nie, A. Leyland, A. Matthews, S.J. Dowey, Surf. Coat. Tech. 122, 73 (1999).

[10] J.F. Sun, Y. Han, K. Cui, Surf. Coat. Tech. 202, 4248 (2008). 